\title{
Sustentabilidad a dos tiempos
}

\author{
María Evelinda Santiago Jiménez*
}

\begin{abstract}
Resumen: Este trabajo revisa los hechos y documentos de organismos mundiales que conformaron el discurso del desarrollo sustentable. Así también, describe cómo el desarrollo sustentable cobra bajo dos lecturas o concepciones muy diferentes efectos, en la sociedad y en el planeta, muy distintos: una construida desde los conceptos desarrollistas y otra que construye un discurso alternativo que toma en cuenta las representaciones sociales y modos de producción de las comunidades originarias donde se hallan los recursos naturales. Los dos discursos nacen de concepciones que promueven la continuación de mundos diferentes: uno, bajo las leyes del mercado y otro, que recupera la (re)creación de los tiempos y nichos culturales y ecológicos. Así también, bajo esta segunda concepción, narra brevemente una experiencia que ha tenido una organización civil en una población tunera de Puebla, Pue. y vinculada a un instituto de educación superior en México.

Palabras claves: Concepciones de desarrollo, desarrollo sustentable, desarrollo sustentable alternativo, experiencias civiles y comunitarias.
\end{abstract}

\section{Sustainability on double timing}

Abstract: This paper reviews facts and documents of world organisms that formed the discourse of sustainable development. It also, describes how sustainable development comes from two different readings or concepts, from very different impacts on society and planet: one built from the concepts of developed and another that builds an alternative discourse that takes into account the social representations and modes of production of the communities where natural resources are. The two languages are born from ideas that promote the continuation of different worlds: one, under the laws of the market and another that retrieves the (re) creation of the times and cultural and ecological niches. Also, under this second conception, briefly recounts an experience that has had a peasant organization of a "tunera" village of Puebla, Pue. and linked to an institute of higher education in Mexico.

Key words: Development conceptions, sustainable development, alternative sustainable development, civilian and common experiences.

\section{Sustentabilidade a dois tempos}

Resumo: Este trabalho revisa os fatos e documentos de organismos mundiais que conformaram o discurso do desenvolvimento sustentável. Assim também, descreve como o desenvolvimento sustentável cobra baixo duas leituras ou concepções muito diferentes, efeitos na sociedade e no planeta muito diferente: uma construída desde os conceitos desarrollistas e outra, que constrói um discurso alternativo que toma em conta as representações sociais e modos de produção das comunidades originarias onde se acham os recursos naturais. Os dois discursos nascem de concepções que promovem a continuação de mundos diferentes: um,

\footnotetext{
* Instituto Tecnológico de Puebla, Puebla, México. Email: evelindasantiago@yahoo.com.mx
} 
baixo as leis do mercado e outro, que recupera a (re)criação dos tempos e nichos culturais e ecológicos. Assim também, baixo esta segunda concepção, narra brevemente uma experiência que teve uma organização civil numa população tunera de Povoa, Pue. e vinculada a um instituto de educação superior em México.

Palavras-chave: Concepções de desenvolvimento, desenvolvimento sustentável, desenvolvimento sustentável alternativo, experiências civis e comunitárias.

Recibido: 28.03.2009

Aceptado: 10.06.2009

$* * *$

\section{Introducción}

Ante la destrucción sistemática de la Naturaleza durante decenios, el discurso del desarrollo sustentable parece una garantía para rescatarla y conservarla; pero lo hace tímidamente con los fundamentos de racionalidad económica (Leff 1998), inspiradores de nuevos desarrollos tecnocientíficos que deshacen la Naturaleza a través de la biotecnología y la definen con nuevos nombres para intervenirla (Escobar 1998 y 1997; Santiago 2007). En este sentido, esas nuevas formas de llamar a la Naturaleza se han convertido en fundamentos para biocolonizar (Shiva 1997) los espacios donde están ubicadas las megadiversidades. Tal forma de apropiación de la Naturaleza presenta a la sociedad dos modos de relacionarse con el medio: uno marcado por la transformación de los recursos naturales en productos, suntuarios y consumidos por una sociedad inconsciente de la devastación que convierte a dichos recursos en basura tecnológica (Beck S/F); y otro que propone estrategias de apropiación racional, enmarcadas por los tiempos de recuperación de los ecosistemas. Pero ¿cómo construir una sociedad alternativa y moderna que no establezca como punto de partida que la Tierra es un banco de negocios?, ¿será posible que la industrialización mundial reconozca que sus procesos tecnocientíficos están devastando a la Tierra y desintegrando a las comunidades?, ¿podría desarrollarse una ética benéfica para la sociedad y la Naturaleza?, ¿qué dimensiones sociales, ecológicas, económicas y políticas deben practicarse para lograr una relación justa con el planeta?, ¿qué decisiones políticas mundiales pueden producir que detenga el empobrecimiento del ciudadano rural y urbano?

Existen serios debates sobre si a los recursos naturales se les etiquetará como privados o colectivos, como es el caso del agua. Por un lado están los impulsos por mercantilizarla como respuesta al escenario de escasez que se pronostica; sin embargo, existen experiencias de comunidades locales, organizaciones sociales, grupos étnicos y organizaciones de mujeres en diferentes países que abanderan luchas por el derecho al agua y construyen alternativas contra la escasez (Becerra 2006). Las culturas alternas ven en el agua una forma de socializar y recrear sus formas de vida, en consecuencia "la cultura de la mercantilización está en guerra con las diversas culturas que comparten, reciben y dan agua gratuitamente. La cultura insustentable, no renovable y contaminante del plástico está en guerra 
con las civilizaciones basadas en la tierra y el barro y con las culturas de la renovación y el rejuvenecimiento” (Shiva 2003). Esta guerra ha llevado a una profunda disparidad en el acceso del recurso hídrico, sin embargo la avaricia de la cultura corporativa se ha armado de estrategias para "administrar” su escasez privatizándola; despreciando la idea de que habría agua para todos si se regeneraran y utilizaran los mantos freáticos dentro de los límites de la renovabilidad (Shiva 2003), entendidos como sistemas culturales dotados de sensibilidad que gestiona una apropiación racional.

La sustentabilidad basada en la privatización deriva en inseguridad porque la toma de decisiones sobre los bienes naturales colectivos controla y priva a los pueblos de su vida productiva, y genera una ruptura social profunda enmascaradora de lo colectivo y lo individual, al privilegiar a unos cuantos por encima de cientos de miles. La concepción occidentalizada de bienestar genera prácticas que generalmente minan la gestión democrática de los derechos sobre los recursos naturales como bien común, deviniendo en pérdida de fertilidad de la tierra y de su capacidad para regenerarse. Además, conlleva un deterioro de de la Naturaleza porque deja de ser un referente vivo para tornarse en producto comercial, tecnológicamente elaborado. Está concepción promueve que los individuos compitan por los restantes recursos colonizados y por los espacios de poder económico y político. Tal realidad deja ver que la sustentabilidad, bajo la visión de las corporaciones, tiene como punto central la racionalidad económica (Leff 1998). Es decir, es la vieja y conocida estrategia desarrollista transformada en discurso liberal del desarrollo (Crush 1998; Escobar 1995; Esteva 1999; Rist 1999; Sachs 1999) por la comisión Brundtland (WCED 1987), ahora maquillada de verde. Es con esta mirada que se definen estrategias medulares que promueven la aceptación de que todos los recursos deben tener títulos y que todo el mundo debe tener derecho a ellos, aunque ese derecho se circunscribe a los que tengan la posibilidad de pagarlos, lo que desemboca también en historias de luchas constantes por la recuperación de una vida digna.

Por su parte, las perspectivas alternativas han sido mayormente cultivadas en países del Sur por intelectuales y técnicos que trabajan regionalmente y tienen contacto con procesos sociales que articulan demandas en términos de defensa del territorio, cultura, desarrollo alternativo, autonomía, autosuficiencia y de diseño y construcción de tecnologías incluyentes y adecuadas. Esta visión contempla que la cultura local y sus habitantes, ubicados en megadiversidades ecológicas o territorios impactados, participan en la recuperación y preservación de sus recursos. Es en este caldero de experiencias locales de resistencia a la privatización, que nace una concepción alternativa basada en el bien común y con los pies en la tierra porque sustenta la inclusión de un aspecto siempre soslayado en las propuestas sustentables: la pobreza.

Una de estas reflexiones sobre la sustentabilidad alternativa la hace Barkin (1998) en Riqueza, pobreza y desarrollo sustentable donde señala que la verdadera sustentabilidad debe tener como derroteros la diversidad, 
la autosuficiencia, el control y la participación locales, la autonomía y la democracia de base; fundamentos de un proceso que lleve a la sociedad a controlar los procesos productivos colonizados por las grandes corporaciones. La historia de las propuestas alternativas versus las propuestas subyugantes no es nueva, las denuncias sobre el problema social y ecológico que hoy vivimos fueron señaladas y previstas décadas atrás.

\section{Las primeras denuncias y tratados}

Primavera silenciosa de Rachel L. Carson (1962) fue una de las primeras denuncias ecológicas que dio inicio al subsecuente mundo de estudios reveladores sobre la irracionalidad y límites del crecimiento económicos. El trabajo de Carson puso en entredicho el modelo de desarrollo capitalista, ella argumentaba que "sólo dentro del espacio de tiempo representado por el presente siglo una especie -el hombre- ha adquirido significativo poder para alterar la Naturaleza de su mundo. Durante el último cuarto de siglo, no sólo ha sido incrementado hasta una inquietante magnitud, sino que ha cambiado sus características con alarmantes atentados del hombre contra su circunstancia: la contaminación del aire, tierra, ríos y mar con peligrosas y letales materias. Esta polución es casi irreparable; la cadena de males empieza tanto en el mundo que debe sostener la vida, como en el propio tejido vivo" (Carson 2001[1962]:19).

Siendo Carson una científica, nos permite decir que su obra no es simple análisis de la tecnología, sino una previsión fundamentada en el conocimiento del abuso extremo al que se estaba sometiendo al planeta a través del uso irresponsable de pesticidas y sus consecuencias en la Naturaleza. La utilización de químicos para incrementar la producción de granos empezó a modificar el entorno biológico; sin embargo, los gobiernos y las empresas argumentaban que todas esas enormes agresiones químicas a la Naturaleza mantendrían la producción agrícola para alimentar un país (EEUU) cada vez más demandante de comida y bienestar. Así entonces, se subordinó al veneno, a un gran número de personas sin su consentimiento y bajo escasa investigación previa sobre las consecuencias en salud social. Carson rechazó rotundamente y puso en tela de juicio el proceder de los especialistas que enfrascados en su propia área negaban el engranaje del que formaban parte. Demandaba someter a una rigurosa investigación los químicos antes de usarlos, no atenderlo era una negligencia para la integridad de la naturaleza y la vida, y una profunda indiferencia por los daños incalculables causados. Esta omisión no la podrán perdonar las generaciones futuras porque "la guerra química, nunca se gana, y toda la vida es atrapada en ese violento fuego cruzado” (Foster y Clark 2008:2). El trabajo de Carson devela que la mercantilización de la vida es el combustible del ambicioso discurso de desarrollo económico. Su libro contiene datos reveladores tales, que colegas, gobierno y empresarios la atacaron encarnizadamente, al grado de solicitar que su libro no se publicara porque su mensaje estaba basado en argumentos de mala fe e histeria femenina (Foster y Clark 2008). 
Ella fue una de las primeras científicas, promotora de la responsabilidad social y ecológica. A partir de su denuncia se devienen las reuniones y tratados que iniciaron la siguiente década. En 1972, participantes de 114 países celebran la primera reunión de las Naciones Unidas llamada Conferencia sobre el Medio Ambiente Humano en Estocolmo, Suecia. De los 114 participantes sólo uno es ministro del medio ambiente -en ese entonces la cartera de medio ambiente no era prioridad de los gobiernos. Los delegados adoptaron 109 recomendaciones para que se comprometieran los gobiernos de los diferentes países participantes. El ideario implícito quedó asentado en la proclama 1 de la conferencia. Explicita la lucha que ha librado la raza humana para sobrevivir en el planeta, pero donde el ser humano ha logrado conquistar y transformar a la Naturaleza gracias al poder incondicional que le otorgan la ciencia y la tecnología. Estas palabras evidencian una concepción de Naturaleza como objeto de transformación tecnológica, que el ser humano tiene el derecho de utilizar indiscriminadamente para alcanzar bienestar, comodidad y larga vida. La Naturaleza no se concibe entonces como un complejo mundo de seres vivos que también tienen iguales derechos de existencia.

En dicha conferencia, también se emitió la proclama 4 dirigida a los países del llamado Tercer mundo, e indicaba que pusieran toda su fe en el desarrollo para disminuir la brecha que tenían con los países industrializados, porque su condición de subdesarrollados los convertía en destructores de los recursos habidos en sus países. Además, conminó a diseñar programas de desarrollo que promovieran un estilo de vida similar al de los países del llamado Primer mundo. Generosamente estos países ponían a su disposición -a través de créditos- los conocimientos científicos y tecnológicos para que instalaran tecnología del Primer mundo para modernizar e industrializar sus sociedades, y como el límite de crecimiento estaba cerca, sugerían salvaguardar el medio. Sin embargo, el reino de la abundancia prometido produjo lo contrario: miseria y subdesarrollo masivos, explotación y opresión sin nombre (Escobar 1999).

En 1972, se realizó la Conferencia sobre Medio Ambiente Humano y coincide con la publicación del reporte Los límites del crecimiento (Meadows et. al. 1972), publicado por el Club de Roma; formado por economistas, científicos y líderes de negocios. Este documento enfatiza que el tipo de desarrollo que prevalecía no era posible sostenerlo interminablemente, concluyendo que si las tasas de crecimiento poblacional, la industrialización, la contaminación, la producción de alimentos y la extracción intensiva de los recursos continuaban así, se alcanzaría el límite de crecimiento en cien años. Su consecuencia probable una repentina e incontrolable declinación de la población y de producción industrial. La solución propuesta en el reporte fue crecimiento cero o estado estacionario para frenar el crecimiento exponencial de economía y población. Se esperaba que los recursos no siguieran siendo socavados por la enorme y creciente demanda habida. El reporte propuso modificar las tasas de desarrollo para alcanzar una estabilidad ecológica sustentable, incluso a largo plazo, mientras el equilibrio global fuera diseñado para que las necesidades básicas de cada 
persona sobre la tierra fueran satisfechas, así como realizar su potencial humano. Es decir, señalaron la necesidad de una distribución igualitaria de los recursos o al menos, una apropiación razonable de los recursos. Utopía que no concuerda con los intereses de los pocos que poseen y lucran con tales recursos.

La reacción de científicos, gobiernos y empresas, ante los señalamientos fue de crítica, fundándose en que el modelo informático utilizado había sido no confiable. Por su parte, algunos economistas criticaron el modelo porque no incluía un mecanismo de precios certero y que atenderlo era riesgoso. También llegaron las críticas de los gobiernos del Tercer mundo, quienes debatieron que apenas empezaban a crecer, cuando se les proponía detenerse. El debate fue intensificado a partir de la aparición del reporte de los límites del crecimiento. Desde ese momento se agudizó la revaloración de la Naturaleza y la urgencia de reconocer los daños socioambientales causados por el proceso del desarrollo. Al fragor del debate, nacen las estrategias del ecodesarrollo, promotoras de nuevos estilos de desarrollo respetuosos de las potencialidades de los ecosistemas y un manejo moderado de los recursos aprovechables (Sachs 1982). Estas estrategias habían sido concebidas después de la aparición de La ley de la entropía y el proceso económico de Georgescu Roegen (1971) quien define los límites físicos que impone la Segunda ley de la termodinámica a la expansión de la producción. Georgescu Roegen expone que el crecimiento económico se alimenta de la pérdida de productividad y desorganización de los ecosistemas y se enfrenta a la ineludible degradación entrópica de los procesos productivos. En sus propias palabras: “[c]ada vez que ocurre algo en el mundo natural, cierta cantidad de energía [disponible] acaba volviéndose inutilizable para realizar un trabajo en el futuro. Parte de la energía no disponible [o inutilizable] se convierte en contaminación, es decir, en energía disipada acumulada en el ambiente planteando una grave amenaza al ecosistema y a la salud pública” (Rifkin y Howard 1990:61).

Georgescu-Roegen desafió al sistema económico existente y planteó romper con el paradigma clásico ya que demostró que promueve un consumo desmedido de los recursos ya que socava mucho más allá de lo que produce, cuando son los recursos patrimonio físico del planeta. Carson, Georgescou Roegen, Meadows, y los reportes oficiales -de manera tímida-, indicaban a todas luces la necesidad de un urgente cambio de rumbo del sistema socioeconómico; pero para el sistema capitalista ese pensamiento no era posible. Así que para mantenerse vigente, no sólo se globalizaron las sociedades, sino que se inició la construcción de nuevos saberes que vistieran de verde al discurso del desigual desarrollo galopante y su indiscriminada explotación de la Naturaleza planetaria.

\section{La sustentabilidad basada en los tiempos del mercado}

Las crisis ambiental y social son producto de conflictos acumulados entre los seres humanos y la Naturaleza; Escobar (1999:75) le llama a este proceso Problematización de la relación entre Naturaleza y sociedad. Se 
han generado estrategias que buscan disminuir tales conflictos, sin embargo, se construyen desde una lente que cosifica los recursos y a la vida misma, resultando diagnósticos que fotografían de manera rígida una realidad que es una compleja dinámica que sostiene la vida en el planeta. Esta interpretación parcial es utilizada como razón suficiente para iniciar un proceso de planificación en la aplicación del conocimiento: se le otorga un valor económico, y quienes tienen posibilidades monetarias para cuidarlos y administrarlos se hacen cargo de ellos en reservas ecológicas o a través de la apropiación de organismos genéticamente modificados, y su almacenamiento en bóvedas ubicadas en lugares reservados sólo a especialistas. Sin embargo, con esta propuesta permaneció la cuestión de los cientos de miles humanos con necesidades básicas insatisfechas, a quienes se les ofrece como solución adquirir recursos regulados por las leyes del mercado que no corresponde a su realidad inmediata.

Para las llamadas corporaciones, lo ideal sería aceptar "[que] todos los recursos deben tener títulos y [que] todo el mundo debe tener derecho a ellos”. (Escobar 1999:79), significaría que los recursos deben de dejar de estar resguardados bajo las leyes colectivas, leyes que algunos pueblos originarios aún practican. El resultado es una lucha política por los recursos donde lo que está en juego es la definición de las formas de concebir su acceso y explotación. En este sentido, para los gobiernos de los países industrializados y las instituciones gubernamentales internacionales, los recursos y el conocimiento tradicional son bienes de la humanidad que cuando son mejorados se convierten en una innovación tecnológica susceptible de ser patentada y finalmente comercializada, sin que los dueños del conocimiento base se beneficien en ningún momento (Santiago 2007). Las estrategias para privatizar recursos y conocimientos se desarrollan para fortalecer procesos de transformación e innovación pero sobre todo de ubicación de los productos en el mercado global, con la anuencia de políticas públicas que ofrecen una gran gama de oportunidades para que las corporaciones crezcan y se vuelvan devastadoramente competitivas (Barkin, Fuente y Rosas 2008), haciéndose pasar por ecológicamente responsables.

Ante ello, el discurso del desarrollo sustentable basado en las leyes del mercado subyuga la realidad a través de su intervención en los saberes tradicionales y con discursos distribuidos como estrategias para mantener al sistema económico hegemónico en el control y el poder. Sin embargo, para desconstruirlos es necesario encontrar las instancias de producción discursiva de poder (cuya función es reglamentar para prohibir) y de producción del saber (Foucault 2005 [1976]). Por ello, es indispensable hacer un recuento histórico de la lucha por definir qué es la realidad, dado que con tal definición se crean políticas e intervenciones que no son neutras respecto a lo social (Escobar, 1999). Bajo estas premisas, se describe el proceso que cambió el discurso del desarrollo económico, por sustentable.

La crisis planetaria de los ochenta llevó a la Unión Internacional para la Naturaleza (IUCN, siglas en inglés), el Programa de la Naciones Unidas para el Medio Ambiente (PNUMA), y el Fondo Mundial para la Naturale- 
za (WWF, siglas en inglés) a publicar la Estrategia Mundial de la Conservación donde nace el concepto desarrollo sustentable bajo tres importantes rubros: el mantenimiento de los procesos ecológicos, el uso sustentable de los recursos y el mantenimiento de la diversidad genética (Enkerlin 1997). A partir de esta conceptualización se define el nuevo discurso como: "La modificación de la biosfera y la aplicación de los recursos humanos, financieros, vivos e inanimados en aras de la satisfacción de las necesidades humanas, para mejorar la calidad de vida del hombre. Para que un desarrollo pueda ser sostenido deberá tener en cuenta, además de los factores económicos, los de índole social y ecológica; [y] deberá tener en cuenta la base de recursos vivos e inanimados, así como las ventajas e inconvenientes a corto y a largo plazo de [los] tipos de acción. (IUCN, WwF, PNUMA 1980)”.

Aunque la definición abraza la idea de incluir factores sociales y ecológicos, no habla de modificar el sentido económico desde sus fundamentos: la apropiación irracional de los recursos, su conversión en productos suntuarios; al contrario, la propuesta avala la carrera desarrollista, pero ahora con la preocupación de preservar, posibilidad alcanzable sólo a través de la aplicación de tecnología que convirtiera a la Naturaleza en mercancía y en objeto de transformación tecnológica (Escobar 1999). En el trasfondo del discurso la recomendación es hacer un recuento de los recursos disponibles para definir las acciones científicas y tecnológicas futuras, es decir, la intervención biotecnológica. Lo interesante de este discurso es que para poder aplicarlo definieron a la Naturaleza como "frágil pero rescatable” a través de la intervención de los expertos, quienes la salvarían, para proseguir con el sostenimiento de un sistema social hegemónico que había y ha demostrado no tener una relación justa con los ecosistemas. Así también, en los años ochenta se presentaron graves acontecimientos que impactaron gravemente a la población mundial: la tragedia de Bhopal, India; la deuda externa de los países del Tercer mundo -México uno de los más afectados-, el descubrimiento del hoyo en la capa de ozono, la amenaza del calentamiento global por las emisiones del dióxido de carbono en la atmósfera, la aparición de la pandemia del sida y el derrame petrolero del tanque Exxon Valdez en Alaska. Con ello, el mercado, la modernización y la industrialización probaron ser ineficientes para lograr un mundo sustentable porque olvidan incluir en sus estructuras tres principios que permiten dar paso a convivencias más justas entre los seres humanos entre sí y con la naturaleza: precaución, equidad intrageneracional (Barkin, Fuente y Rosas 2008) y equidad intergeneracional.

El caos ambiental fue el resultado principalmente de tres factores convergentes: a) la mayoría de las industrias ubicadas en los grandes conglomerados urbanos habían sobrepasado los límites de emisiones contaminantes y grandes cantidades de desechos domésticos, provocaban alteraciones en el ambiente de magnitud poco medibles, pero muy perjudiciales (Wackernagel 1996); b), el desarrollo económico prevaleciente, fincado en la premisa del beneficio monetario, violenta desde entonces el ámbito rural con la política de industrializar el campo, dejando a las comunidades campesinas del Tercer mundo con pocas posibilidades de sobrevivir con méto- 
dos de siembra tradicional, al aplicar la agricultura capitalista que deteriora los nutrientes y la fertilidad de los suelos (Barkin 1991); y, c) la internacionalización del capital que finalmente hoy ha redundado en la bursatilización de las economías, con consecuencias desfavorables para millones de residentes urbanos que actualmente viven con salarios miserables, sufriendo el desempleo involuntario debido al uso de nuevas tecnologías que desplazan la fuerza de trabajo (Rifkin 1996).

El Primer mundo hizo esfuerzos por entender y remediar la catástrofe señalada, y reconoció que no sabía cómo revertirla, aunque nunca consideró disminuir las comodidades de la modernidad. Ante esta disyuntiva y para sanar con discursos al planeta, el derroche de palabras continuó y una vez más en los ochenta, la Organización de las Naciones Unidas (ONU) promovió la conferencia Estocolmo+10 en Nairobi. Se concluyó urgente realizar investigaciones para generar un documento declaratorio que expresara una seria preocupación por el estado del ambiente y tuviera el objetivo de conocer a fondo el problema. A partir del planteamiento hecho en Estocolmo +10, en 1983 la onU establece una comisión independiente para diseñar una agenda global para el cambio a la que llamaron Comisión Mundial sobre el Medio Ambiente y el Desarrollo (WCED, siglas en inglés). Con el cometido de conocer a fondo el problema ambiental, el grupo trabajó durante tres años bajo la coordinación de la Primera Ministro Noruega Gro Harlem Brundtland. En 1987 publican el reporte Nuestro futuro común que describe las crecientes tensiones habidas entre el medio y la economía, y el binomio Naturaleza y sociedad (Escobar 1999). Propone como solución cambiar el discurso del desarrollo económico por el de desarrollo sostenible, único camino visible seguro para la estabilidad política y ecológica del mundo. Pero igual que la definición expuesta en Estrategia Mundial de la Conservación, el tratamiento continuó apoyando el desarrollo económico de las sociedades; la diferencia radicaba en que el reporte señala a la Tierra como una víctima a la que hay que rescatar: “[...] una esfera frágil y pequeña dominada no por la actividad y las diligencias humanas, sino por un conjunto de nubes, océanos, verdor y suelos” (WCED 1987:1).

Al igual que Harry Truman ${ }^{1}$ declaró en 1949 la necesidad y deber de rescatar al Tercer mundo, Nuestro futuro común (WCED 1987) fue el discur-

\footnotetext{
1 "Cuarto, debemos embarcarnos en un nuevo programa que haga disponibles los beneficios de nuestros avances científicos y progresos industriales para el mejoramiento y el crecimiento de las áreas subdesarrolladas. Más de la mitad de la población del mundo vive en condiciones cercanas a la miseria. Su alimentación es inadecuada. Son víctimas de las enfermedades. Su vida económica es primitiva y de privaciones. Su pobreza es un defecto y un peligro para ellos mismos y para las áreas más prósperas. Nuestro principal objetivo será ayudar a los individuos libres del mundo, a través de sus propios esfuerzos, para producir más alimento, más vestido, más material para la casa-habitación, y más poder mecánico que disminuya su carga. Esta deberá ser una empresa cooperativa en la cual las naciones trabajen juntas a través de la Naciones Unidas y sus agencias especializadas [específicamente con el Banco Interamericano de Desarrollo (BID)]. Deberá ser un esfuerzo mundial para alcanzar la paz, la plenitud y la libertad. [Además], [1]a experiencia muestra que nuestro
} 
so detonante para que el engranaje científico, tecnológico y político se preparara para planificar el desarrollo de estrategias de rescate de la Tierra. Curiosamente, este nuevo discurso de rescate y administración de los recursos naturales fue otorgado a los científicos occidentales argumentando que el conocimiento útil sólo lo tiene el mundo occidental, y desacreditando para ello, al conocimiento tradicional. No es de extrañar, que en estos días de crisis ambiental, el conocimiento tradicional haya cobrado una gran importancia porque es resultado de la experiencia acumulada a través de siglos de relación con los ecosistemas; es entonces, una codiciada fuente de saber útil para desarrollar ciencia y tecnología sustentable para ser usufructuada, patentada y puesta en las vitrinas por el mercado globalizado.

Occidente se desgarra las ropas en Nuestro futuro común (wCED 1987) pero no declara inoperante el discurso de la carrera por el desarrollo; al contrario, presupone que la problemática social y ambiental podrá ser resuelta en el futuro a través de la tecnificación y modernización paulatina de las sociedades del Tercer mundo "[reproduciendo] el [viejo] lema: civilizar es poblar y no hay mejor poblador que el hombre blanco y su tecnología” (Roitman 2009). En este sentido, se puede decir que la temática encerrada en el reporte Brundtland representa la misma visión del desarrollo occidental sin cambios de fondo; aún cuando se presenta como remedio a los efectos contaminantes y como política conservacionista de la Naturaleza.

El lenguaje de Nuestro futuro común (WCED 1987) encierra una nueva lucha política por la colonización de los últimos espacios socioculturales del Tercer mundo y el control del aparato productivo mundial; seduce a todo aquel que lo escucha porque es piadoso e incita al rescate del Planeta. El discurso del desarrollo sustentable tiene la magia de encantar a los pueblos, los hace caminar hacia el encuentro de un nuevo canto de sirenas (Korten 1999): la mercantilización de su biodiversidad (Santiago 2007). La cara oculta de la sustentabilidad de Brundtland es "garantizar el control de las corporaciones del Norte [sobre] el material genético de las especies biológicas de todo el mundo, la mayoría de las cuales están en el Sur” (Escobar 1996:372). Los pueblos del Tercer mundo, con esta nueva versión del desarrollo están en riesgo de perder su cultura, su tierra y su saber tradicional; es decir, todo lo que hasta ahora los constituye y da existencia.

En el discurso científico del Primer mundo se plantea que el crecimiento económico y el desarrollo seguirán involucrando cambios físicos en los ecosistemas, es decir que no existirá alguna parte del planeta donde

comercio con otros países se expande a medida que ellos progresan industrial y económicamente”. Public Papers of the Presidents of the United States - Harry S. Truman (19451953). Jan. 1 to Dec, 31, 1949: 114-115. Versión corta del punto cuatro de la charla inaugural de Truman el 20 de enero de 1949. Traducción libre de la autora. 
éstos podrán ser conservados intactos. Consideran que es necesario realizar una planeación de los impactos en aire, suelo y agua, que esté fundamentada en llevar todos los beneficios posibles para la humanidad. Sin embargo, parece olvidar que tales ecosistemas están ubicados en el Tercer mundo, y dichos beneficios los obtendrían las corporaciones del Primer mundo. Desde esta perspectiva, parece ser que el desarrollo sustentable, promueve la recolonización "sustentable” de la periferia. Eduardo Galeano en la introducción de su libro Las venas abiertas de América Latina describe lo anterior de una manera magistral: "la región sigue trabajando de sirvienta. Su existencia está para el servicio de necesidades ajenas, como fuente de petróleo y hierro, cobre y carne, frutas y café, las materias primas y alimentos con destino a los países ricos que ganan consumiéndolos, mucho más de lo que América Latina gana produciéndolos” (Galeano 2004 [1971]:15).

En la actualidad la Iniciativa de Integración de la Infraestructura de Sur América (IIRSA) traduce de manera fiel lo escrito por Galeano hace más de 30 años, ya que propone apoyar las negociaciones internacionales de integración comercial -Área de Libre Comercio de las Américas (ALCA), Comunidad Suramericana de Naciones (cNs) y los Tratados de Libre Comercio (TLC). La Iniciativa tiene el objetivo de proveer de la infraestructura que modernice e industrialice Suramérica para que al fin pueda ser desarrollada (Flórez 2007). En el cuadernillo 19 de la revista Biodiversidad del Foro Boliviano sobre Medio Ambiente y Desarrollo (FOBOMADE) y del Instituto para la Inclusión Social y el Desarrollo Humano (INCLUIR) (2004:2) describen al IIRSA ${ }^{2}$ como "[...] un plan para construir infraestructuras en América del Sur. Con ellas las empresas privadas podrán sacar y transportar recursos naturales y mercancías. Se construirán rutas, ferrocarriles, hidrovías, puertos, gaseoductos, oleoductos, acueductos, telecomunicaciones. Los gobiernos se endeudarán para construir estas obras. Y en vez de mejorar la calidad de vida de la población solamente mejorarán las ganancias de las empresas. El Presidente del Banco Interamericano de Desarrollo (BID) en una de sus charlas dijo al respecto: "La integración física regional, [...] se ve dificultada por las formidables barreras naturales que impone la geografía del continente, [por ello] ha sido desafortunadamente un objetivo relegado. Sin embargo, el desarrollo de la ciencia y de la técnica nos abre hoy inmensas posibilidades que permiten responder a las oportunidades que ofrece una geografía que ya no puede ser considerada un obstáculo sino una oportunidad" (BID, CAF, FONPLATA 2000:14). Es decir, la Naturaleza indomesticable hasta entonces, se convirtió en un parpadeo, en un objeto a transformar por la ciencia y la tecnología con el deseo de hacerse, al fin, del tan perseguido desarrollo de América Latina, como lo indicara en 1949, Harry Truman ${ }^{3}$.

\footnotetext{
${ }^{2}$ Para conocer las políticas y documentos que se han diseñado en pro de la IIRSA visitar: http://www.iirsa.org

${ }^{3}$ El subrayado es de autor.
} 


\section{La sustentabilidad basada en los tiempos de la diversidad}

A diferencia del objetivo que persigue la sustentabilidad del Norte, la del Sur recrea el término para instrumentar luchas contra la pobreza y la explotación capitalista de la Naturaleza. Estas luchas están íntimamente ligadas a la defensa del territorio regional y no sólo por la defensa del espacio que definen los gobiernos. En este sentido, urge concebir los problemas ecológicos en términos de la diferenciación de los ecosistemas por regiones, contemplando factores como las fuentes de energía natural; las formas de apropiación de los recursos naturales; los sistemas productivos existentes ya sea tradicionales o inducidos; y las formas de disposición de los residuos orgánicos e inorgánicos; prácticas tradicionales de disposición y prácticas actuales de disposición, así como los beneficios que dan a la población originaria de tal sitio. Tomar en cuenta estos aspectos permite no caer de manera precipitada en la homogenización del ambientalismo global. "La perspectiva latinoamericana del desarrollo sustentable le da importancia a aspectos no tomados por Brundtland en forma adecuada como la deuda externa, la caducidad de los modelos de desarrollo convencionales, las desigualdades, la deuda ambiental histórica de los países del Norte, la importancia de respetar el pluralismo cultural y la protección del patrimonio natural y genético de la región (Escobar 1999:79)". Para el Tercer mundo se ha convertido en una estrategia de defensa del territorio. Los pueblos rurales están reconociendo que existe un súbito interés por la riqueza ambiental ubicada dentro de sus territorios. Esto inició un proceso de concientización sobre la importancia de tales recursos, específicamente, cuando descubren que existe una necesidad urgente de recuperar y preservar muchas de las especies de flora y fauna. Esta premisa está siendo tomada como una estrategia para la defensa y control del territorio (Barkin 1998), además es una oportunidad para ganar espacios políticos dentro de la sociedad dominante.

Sin embargo, esta nueva colonización ecológica puede tener dos efectos negativos para los pueblos rurales: por un lado, expropiarles y despojarlos de su territorio por considerarlos depredadores de esos últimos espacios paradisíacos. Por otro lado, etiquetarlos como parte del paisaje ecológico y evitar su extinción, responsabilizándolos del cuidado del bosque sin tener ellos la posibilidad de participar en el diseño de los programas de desarrollo por ser objeto de la recuperación, preservación y trivialización (o ridiculización folclorizante) de sus culturas. "Se puede decir que el problema fundamental de los programas de desarrollo del Norte es que la relación con el medio ambiente depende a menudo de una clasificación de los pueblos indígenas como parte de la "fauna" de la zona. (...) Los representantes del paradigma Salvemos la Tierra como el Banco Mundial, el BID y otros grupos internacionales, simplemente consideran los asuntos indígenas como asuntos ecológicos” (Assies et al 1999:12). Este concepto erróneo que se tiene sobre las culturas campesinas es visto con respeto dentro del discurso sustentable alternativo basado en la diversidad social y ecológica. Reconoce que la actualización ${ }^{4}$ (léase: recuperación

${ }^{4}$ Esto no significa que las comunidades regresen a sus formas antiguas de organización sino
que reinventen, recreen y perseveren para sí, los conocimientos heredados por sus abuelos, 
del conocimiento erosionado por la intervención de “expertos”) de los comportamientos de los habitantes rurales son vitales, ya que se han labrado a través de la relación cotidiana con la Naturaleza. La importancia de este conocimiento para la sustentabilidad basada en la diversidad se encuentra enmarcada en tres dimensiones a recuperar: a) la definición de la relación tierra-hombre en la producción de sus alimentos y satisfactores básicos; b) la conceptualización que el hombre hace de tal relación, es decir, su cosmovisión que incluye mitos, conocimientos, prácticas y saberes; y, c) el rencuentro del vínculo entre la especie humana y la diversidad de especies en el mundo natural (Toledo 1997: 111-135).

Este reconocimiento debe dimensionarse con las formas productivas que las comunidades indígenas y rurales poseen porque regularmente son las menos dañinas para los sistemas ecológicos ya que han funcionado por siglos para la conservación de la diversidad biológica y paisajística y, aunque hoy se clasifiquen como depredadoras -debido al despojo territorial del que han sido protagonistas-, tal deterioro no tiene las dimensiones de socavo ambiental que históricamente han producido y producen en el mundo los países desarrollados; por el contrario, las prácticas comunitarias funcionan sobre concepciones de conservación y regeneración de sus ecosistemas.

Las características anteriores hacen que un número de comunidades relegadas y olvidadas en el Tercer mundo hayan decidido aceptar el súbito interés de Occidente -inyectar capital para reconstruir la riqueza naturalcomo una oportunidad para fortalecerse y al mismo tiempo encontrar "alternativas al desarrollo y no de desarrollo, es decir, la superación de lo imaginario convencional del desarrollo de tipo eurocéntrico” (Escobar 1995:403). A este proceso se le ha definido también como el ambientalismo de los pobres ${ }^{5}$ (Toledo 2000). Hoy, el concepto ha sido retomado por lo teóricos del Sur como una estrategia de rechazo al discurso desarrollista y persigue un fin común: la desconstrucción del paradigma occidental. Es decir, su formulación está matizada por la diferencia, ya que incluye las experiencias de las diversidades locales: defiende el conocimiento local y la diversidad socio-cultural, mira críticamente los discursos científicos vigentes, y defiende y promueve los movimientos locales y pluralistas (Escobar 1995).

Leff (1998) argumenta que el principio de la sustentabilidad en el Sur es una marca límite y un signo que reorienta el proceso civilizatorio porque reintegra los valores y potencialidades de la Naturaleza, las externalidades sociales, los saberes subyugados y la complejidad del mundo negados por la racionalidad mecanicista, simplificadora, unidimensional, fraccionadora, que ha conducido al proceso de modernización. El concepto

amalgamados en una versión menos agresiva de la cultura occidental y menos atada a los compromisos desarrollistas y negativos de la globalización (mercantilismo y usura).

${ }^{5}$ Toledo (1999:4).describe el ambientalismo de los pobres como luchas por demandas ecológicas que constituyen un salto delante de las otras luchas del campo rural, ya que articulan la defensa de la Naturaleza, la producción y la cultura. 
de ambiente es un saber reintegrador de la diversidad ecológica y sociocultural, de nuevos valores éticos y estéticos, de los potenciales sinergéticos que genera la articulación de procesos ecológicos, tecnológicos y culturales (Leff 1998: 15-18).

Lo anterior está promovido en la Agenda 21 aunque no de forma extensa, se reconoce que los proyectos deben integrar todas las diversidades que existan en un territorio para evitar una mayor devastación de los recursos, ya que los pueblos indígenas tienen mucho que ver en la mitigación de la crisis ambiental porque ellos han generado a través de los tiempos un conocimiento científico tradicional holístico. La Agenda 21 declara: “...debe reconocerse globalmente que las tierras de los pueblos indígenas deben ser protegidas de actividades que sean ecológicamente dañinas y de las acciones que los pueblos indígenas consideren ser social y culturalmente inapropiadas. En este sentido, debe haber reconocimiento que la dependencia tradicional en los recursos renovables y los ecosistemas, incluyendo la agricultura sustentable, continúa siendo esencial para el bienestar cultural, económico y físico de los pueblos indígenas. Algunos pueblos indígenas pueden requerir un mayor control sobre sus tierras y una mayor oportunidad para administrar sus recursos, incluyendo la participación en el establecimiento y administración de las áreas protegidas" ${ }^{6}$ (Sitarz 1994: 269).

La importancia de estructurar proyectos que integren la diversidad cultural y social estriba en evitar la pérdida de hábitats a través de la construcción de megaproyectos de desarrollo como el erigido en 1984 en la Costa de Oaxaca (Barkin y Paillés 2002; Barkin y Paillés 2000; Santiago y Barkin 2006; Santiago 2004). Como ya es típico de estos proyectos, dentro de su diseño no se considera ni remotamente el compartir con los habitantes originarios el progreso traído por las transnacionales. En una palabra, tanto para el Estado como para las corporaciones y la burocracia del desarrollo los habitantes rurales son objetos desechables porque su pasado, su presente y su futuro son borrados con la firma de un convenio en algún lugar lejano y lujoso, empujando el destino de la flora, la fauna y los habitantes de la región hacia la extinción. Contrariamente, la nueva concepción integral del uso de los recursos naturales se reconcilia con aquello erosionado por la concepción capitalista de la Naturaleza.

La conceptualización alternativa del Sur no establece como un hecho que los indígenas y campesinos sean personajes que interactúan de manera sustentable con sus entornos y evita a toda costa de culpar a la víctima de su propio mal cómo se hace en el Reporte Brundtland. Inversamente, enfatiza que lo sobresaliente de estas sociedades de subsistencia es que su conocimiento no es sistematizado, es un conocimiento empírico renovado en la práctica, principalmente porque es “recopilado” a través de la socialización constante con la Naturaleza. En este sentido, la participación de las bases (Barkin 1998) en la (re)construcción constante

${ }^{6}$ Traducción libre de la autora. 
del discurso de la sustentabilidad es lo que le aleja de la rigidez propia de los diseños de escritorio. Sin embargo, las sociedades ubicadas en la riqueza natural y la pobreza material, aún no están capacitadas en los saberes occidentales; por lo tanto -para bien o para mal- las intermediarias "al desarrollo" (Escobar 1995) son las onG's, quienes generalmente llevan sus casos ante las agencias burocráticas internacionales o nacionales. Esta participación virtual, guarda la frágil esperanza de la ética a prueba de fuego de que la agencia sirva como "articuladora de culturas". No obstante, para el éxito es necesaria la participación de las bases como "prerrequisito fundamental para cualquier programa de sustentabilidad, ya que la mayoría de los análisis técnicos destacan que los patrones que perpetúan estas desigualdades conducen a una mayor degradación del ambiente” (Barkin 1998:61).

Una verdadera participación en el diseño de proyectos que impacten y provean el control del territorio, promueven no sólo la autosuficiencia de los pueblos rurales sino también, fortalecen sus sociedades económica, social y políticamente; consecuencia de ello es la recuperación y conservación de los ecosistemas donde están inmersos porque serán la materia prima para la reconstrucción de su proyecto de vida. Además, al mismo tiempo pueden continuar siendo el suministro de los mismos servicios ambientales que hasta ahora han proveído -actividad no valorada por el resto de la sociedad.

La falta de inclusión de la diversidad social y ecológica en los procesos de reproducción social vigentes, ha llevado al planeta a vivir una crisis ambiental cada vez más patente. Los fundamentos de esta crisis no es otra cosa que una crisis de una civilización "que depreda la Naturaleza y subyuga a las culturas alternas. El modelo civilizatorio dominante degrada al ambiente, menosprecia la diversidad cultural y discrimina al Otro (al indígena, al pobre, a la mujer, al negro, al Sur) mientras privilegia el modo de producción explotador y un estilo de vida consumista que se han vuelto hegemónicos en el proceso de globalización (Manifiesto por la vida 2004:16)" La sustentabilidad basada en la diversidad social ${ }^{7}$ y ecológica promueve premisas que podrían considerarse irreconciliables con el sistema capitalista, pero son importantes porque se basan en la construcción de estrategias que sirvan para seguir sosteniendo la vida en el planeta; estas premisas tienen que ver con las dimensiones ecológicas, sociales, económicas y políticas. En primera instancia se encuentra la dimensión ecológica que demanda la potencialización y preservación de los ecosistemas que no pueden seguir subyugados a los tiempos de productividad industrial que alimentan las necesidades de consumo de las clases medias del mundo.

${ }^{7}$ Eduardo Galeano (1989:5) en El libro de los abrazos hace una descripción bella sobre la diversidad social: "Cada persona brilla con luz propia entre todas las demás. No hay dos fuegos iguales. Hay fuegos grandes y fuegos chicos y fuegos de todos los colores. Hay gente de fuego sereno, que ni se entera del viento, y gente de fuego loco que llena el aire de chispas. Algunos fuegos, fuegos bobos, no alumbran ni queman; pero otros arden la vida con tanta pasión que no se puede mirarlos sin parpadear, y quien se acerca, se enciende”. 
La dimensión social trata sobre la demanda de la aplicación de principios éticos basados con la equidad intergeneracional e intrageneracional y la justicia social. Su aplicación es importante desarrollarla en un marco multidisciplinario, con un acercamiento plural y una perspectiva histórica que considere las herencias culturales, materiales y medioambientales (Barkin, Fuente y Rosas 2008:1); así como los saberes sometidos, etiquetados por la civilización hegemónica como una serie de saberes que los descalifican como saberes legítimos: ingenuos, jerárquicamente inferiores, por debajo del nivel del conocimiento o sin la cientificidad obligada (Foucault 2002 [1997]). Por otra parte, la concepción alternativa de la sustentabilidad es una estrategia integral e incluyente que asegura la calidad de los productos científicos y tecnológicos entregados a la sociedad, urbana o rural. La premisa de esta alternativa estriba en valorar los productos tecnocientíficos no sólo por los científicos, sino que también por una comunidad amplia de pares extendidos (Funtowicz y Ravetz 2000) constituida por la diversidad social.

La dimensión económica promueve una redefinición de la actividad nacional y global que considera las necesidades materiales e inmateriales de las localidades como su columna vertebral, que pueden ser vistas como áreas de oportunidad, y no como insuficiencias, para potenciar el desarrollo de los sistemas de producción locales, racionales y acordes a los tiempos de reproducción de los ecosistemas. Es decir, se trata de la construcción de estrategias de acumulación no capitalista (Rosas 2009).

Por último la dimensión política permitirá a la sociedad rural establecer negociaciones con las diferentes estructuras socioculturales, haciendo posible que la sociedad pueda definir qué aspectos relevantes de los sistemas económicos, científico tecnológicos se apropiarán, reinventarán o desecharán. El aspecto político promueve la participación activa y directa de los actores locales a través de estructuras de gobierno que los incluya y ejecute el mandato colectivo presente y futuro. Busca alternativas éticas a través de redes de acción social donde prevalezcan las relaciones horizontales, nutridas por consideraciones de reciprocidad, confianza y cooperación; así como alejadas de esquemas centralizados y verticales, que forman cotos de poder. No obstante, la manera particular de los habitantes para participar en la sustentabilidad depende principalmente de sus condiciones locales, que incluye características tangibles como los recursos naturales e instituciones locales, así como la madeja de relaciones y organismos que definen la producción y los procesos de organización para la toma de decisiones y del seguimiento del ejercicio de la autoridad, así como sus prácticas religiosas (Santiago 2009).

\section{Los tiempos de la diversidad social en la búsqueda de la sustentabilidad}

La aplicación del discurso desarrollista con el tiempo ha logrado desmantelar el campo. Buscando aumentar la producción de la tierra, grandes territorios hoy son infértiles por el uso de agroquímicos. Para remediar 
los impactos ocasionados a naturaleza y personas, el discurso del desarrollo se disfraza de verde y se hace llamar desarrollo sustentable. Sin embargo pese a un gran número de esfuerzos por definirlo y realizarlo, aún no existe consenso sobre qué es y qué no el desarrollo sustentable, para la población no especializada, particularmente, la sociedad rural que está ampliamente involucrada y tiene intereses directos en esto. Blauert y Zadek (1999) hablan de la existencia de un problema de comunicación y de interpretación de prioridades y de valores que varían en cada grupo social y contexto, luego entonces el desarrollo sustentable es desarrollado, o mejor dicho, apropiado por las sociedades rurales conforme sus prácticas cotidianas con las cuales buscan espacios donde concretar sus intereses personales, familiares y comunales para construir y reproducir su proyecto de vida. Sin embargo, durante el proceso existen desacuerdos que llegan a rompimientos, abandonos (Santiago 2009; Santiago y Barkin 2006) o hasta violencia. Sin embargo, también se construyen proyectos sustentables con premisas esperanzadoras.

En este apartado hablaremos sobre el proceso que se está llevando a cabo en una comunidad campesina del Estado de Puebla llamada San Sebastián Villanueva, ubicada en el municipio de Acatzingo. En esta comunidad campesina existen ejidatarios organizados en un grupo llamado Sociedad Productiva para el Desarrollo de Villanueva (SOPRODEVI). Una de sus características es que está conformado por 6 mujeres y 3 hombres unidos para definir cómo construir un proyecto alternativo de existencia que les permita no sólo reconstruir su proyecto de vida sino rescatar y conservar el ecosistema de su territorio, ya que consideran importante poder heredar a sus hijos espacios "lo más limpios posible”. Otra de las características marcadas del grupo es su gran interés por formar alianzas distintas a las que hacían los campesinos para sobrevivir: con organizaciones manejadas por el partido y gobierno (Partido Revolucionario Institucional -PRI-) durante varias décadas ${ }^{8}$. La decisión de realizar estas nuevas alianzas los ha llevado a construir una red que les permita desarrollar diagnósticos y metodologías de investigación adecuadas a su realidad local. Con ello han podido apropiarse de conocimientos que les dan herramientas para realizar mejores consultas, así como estructurar proyectos fundamentados para acceder a recursos. Están también creando formas de organización para ser autónomos sin poner el control de su organización en manos de organismos dependientes del gobierno. En estos momentos soprodevi está aliada a la Fundación $\mathrm{ADO}^{9}$ (Autobuses de Oriente) y al Instituto Tecnológico de Puebla (IтPue), ambas instituciones buscan con la sociedad estrategias para su proyecto de vida. Las relaciones que este tipo de organizaciones establecen son también respuesta a las fallas del mercado y quiebra del Estado. Las poblaciones o parte de ellas son impulsadas a entrar en procesos de organización local autónomos de las estructuras políticas y gubernamentales. Es-

\footnotetext{
${ }^{8}$ Sin embargo, aún existe este proselitismo, pero ahora bajo el manto protector de otro partido político.

${ }^{9}$ http://www.fundacionado.org.mx/
} 
tas acciones colectivas llevan a las organizaciones de base a articularse en red, lo que les permite consolidarse; asumir proyectos en el marco de unas pocas organizaciones y entablar nuevas relaciones con actores que amplían sus posibilidades (otras redes, ONGs, organismos internacionales, instituciones educativas, entre otras).

\section{La Sociedad productiva para el desarrollo de Villanueva (SOPRODEVI)}

El pueblo de Villanueva está dedicado en su totalidad a la producción de nopal verdura y nopal fruta desde hace 30 años. Las carencias alimenticias y materiales los empujaron a abandonar la siembra de los productos que tradicionalmente consumían. Además saber, en aquel momento, que existía una gran demanda por el cactus los llevó a tomar la decisión de impactar severamente su territorio arrasando no sólo con sus terrenos de siembra, sino también bosques para convertirlo en el territorio de la tuna y el nopal, en monocultivo.

SOPRODEVI nace en 2004 con el objetivo de buscar estrategias que contrarresten la demanda fluctuante que hasta hoy existe del nopal y la tuna $^{10}$. Reconoce que debe darle un valor agregado a sus productos y dejar de ofrecerlos en fresco. Al mismo tiempo está consciente del daño que se ha ocasionado a los ecosistemas, específicamente por la introducción de una especie no nativa de su territorio, también son sabedores del impacto en la salud de los habitantes que produce el uso indiscriminado de fertilizantes y plaguicidas. La búsqueda de alternativas fue posible, gracias a que un familiar les regaló cinco kilos de lombrices. Así es como se inicia la formación de una red que va incluyendo diversos actores sociales con distintos conocimientos y relaciones que fortalecieron las acciones colectivas de la sociedad. Primero se vincula con la Fundación ADO y después con el Instituto Tecnológico de Puebla. La premisa de la relación es considerar a los ejidatarios pares extendidos (Funtowicz y Ravetz 2000) ya que conjuntamente con los pares tradicionales analizan los problemas, diseñan los procesos que benefician a la colectividad y entre ambos recrean en la práctica el conocimiento. Sin embargo, a pesar de la voluntad de introducir programas sustentables, el proceso de recuperación de las siembras tradicionales es lento porque la comunidad considera más importante alimentar a su familia que dejar el monocultivo ya que todavía lo consideran una promesa.

\footnotetext{
${ }^{10}$ La tuna y el nopal tienen dos periodos de cosecha y venta, el primero es en junio-agosto al que los campesinos le llaman la temporada alta y el precio que les paga el mercado por 20 kilos fluctúa entre $\$ 300.00$ y $\$ 350.00$ (aprox. 30 o 35 dólares americanos) después de esos meses el precio por 20 kilos es de \$20.00 (aprox. 2 dólares americanos). Entonces las familias de San Sebastián obtienen un mayor ingreso durante sólo tres meses. Al igual que la mayoría de los campesinos de Latinoamérica una estrategia para obtener ingresos recurren a la migración para los EEuU, yéndose los más jóvenes al egresar de la secundaria, desintegrando a las familias y dejando la carga del campo a las mujeres.
} 
Hoy se ha convertido en un callejón sin salida ya que enfermedades como el cáncer son consecuencia de la utilización de fertilizantes y pesticidas, que como en otros sembradíos, se usan en la tuna y el nopal.

Algunos de los miembros de soprodevi han enviado a sus hijos a escuelas donde se promueve la construcción de estrategias para lograr un desarrollo rural sustentable alternativo ${ }^{11}$, esta acción les ha permitido introducirse en espacios donde convergen investigadores, académicos, empresarios y ONG's, dándoles la oportunidad de relacionarse para crear vínculos estratégicos que les permiten acceder a recursos antes no solicitados como son financiamientos, conocimiento, espacios para generar tecnologías adecuadas a su estilo de vida y a sus ecosistemas, pruebas de laboratorios a precios más accesibles, etcétera. La educación de sus hijos ha tenido resultados ya que no han migrado -y mejor aún-, han apoyado y animado a sus padres a que trabajen sus tierras de otra manera. En este sentido los jóvenes aportan conocimiento, información y son un vínculo que relaciona a la organización con académicos comprometidos con el desarrollo sustentable del campo. Por ejemplo, la unión de los conocimientos de padres e hijos les ha dado la visión para conformar negociaciones estratégicas que van más allá de las solicitudes de apoyos gratis al Instituto Tecnológico de Puebla. Han hecho relaciones donde ellos se convierten en pares extendidos (Funtowicz y Ravetz 2000) para evaluar y llevar a cabo un proyecto de investigación ${ }^{12}$ con profesores-investigadores de la institución educativa. Por ejemplo, se firmaron dos acuerdos de colaboración y un comodato para que mantuvieran en su territorio artefactos tecnológicos y se hicieran cargo de ellos. La finalidad es que utilicen esos equipos tecnológicos en actividades que les rindan beneficios a todos los integrantes de SOPRODEVI, resguardando la información en una bitácora, misma que comparten con los profesores-investigadores para que estos últimos le de un formato científico.

El intercambio de saberes y relaciones establecido ha beneficiado a ambas partes porque la sociedad recibe aparatos técnicos, trabajos de consultoría, planes de negocios, una página web, y el ıтpuebla información recopilada por los campesinos para adecuar a la realidad social y ecológica tanto los sistemas técnicos como los aparatos. Si bien es cierto que el intercambio de saberes está fundamentado en la buena fe, la confianza y la reciprocidad, también se enmarca con reglas de cooperación y coordinación que desde su inicio soproDEvi estableció para el buen funcionamiento de las negociaciones. Otro aspecto importante es que la sociedad ha tenido el cuidado de legitimar a un líder, así como también ha nombrado ejecutivos con funciones de gestión y administración, de esta manera genera ámbitos y estructuras para el trabajo en equipo. Estas formas de organizarse son la plataforma para cuidar las normas establecidas para permanecer

\footnotetext{
${ }^{11}$ http://cesder-prodes.org/index.htm

${ }^{12}$ Estudio integral de la franja tunera Las Villanuevas: sociedad, tecnología y medio ambiente. Proyecto de investigación financiado por la Dirección General de Educación Superior Tecnológica.
} 
cohesionados y mejorar la vida de sus miembros y de la comunidad.

Por otro lado, la confianza que la sociedad establece con el Instituto Tecnológico de Puebla está fincada principalmente en los resultados y beneficios que los sistemas técnicos puedan tener para ella. En este sentido, se puede decir que la confianza está dividida en dos rubros importantes: la confianza estratégica, es decir la esperanza de la investigación tenga un beneficio que fortalezca sus proyectos de vida individuales y colectivos; y la confianza técnica, con la que espera adquirir capacidades y competencias que les permiten acceder a mercados que son difíciles, si son desconocidos. Debe decirse que la confianza normativa que practican en la comunalidad, sus creencias y valores; sin embargo, la ponen en la mesa de las discusiones al dialogar sobre cómo se operarán los sistemas técnicos dentro del contexto sociopolítico, económico y cultural.

Esta propuesta de desarrollo sustentable enmarcado en la diversidad aún está en proceso, se negocia ahora la definición de qué otros actores sociales deben incluirse para que los procesos productivos tradicionales se innoven sin causar conflicto, pero sobre todo se negocia de manera adecuada para que la red formada entre los miembros de la sociedad y los académicos tenga una estabilidad prolongada. Realizan reuniones periódicas de dos tipos, una donde los líderes de la sociedad agotan todas las dudas que puedan tener sobre su participación como pares extensos, y una segunda donde participan todos los miembros para aclarar dudas. Los académicos responden siempre a sus preocupaciones en cuanto a cuestiones tecnológicas que signifiquen un riesgo social, lográndose un diálogo mutuo abierto y redondo.

Finalmente, se espera que a través de la participación de la sociedad como pares extensos, se fortalezca la autonomía en dos sentidos: la autonomía individual para que logren tener una capacidad de elección adecuadas a sus intereses, y construyan estrategias familiares que les lleven a concretar procesos de autosuficiencia y de autonomía política cultivando su capacidad colectiva de autorregular este sistema que han construido a través de los años. Ambas autonomías les confieren la capacidad de negociación ante diferentes actores sociales y organizaciones con quienes establecen relaciones que les lleven a ampliar sus redes.

\section{Conclusiones}

Las dos formas de concebir la sustentabilidad que se describen en este documento parten de concepciones distintas de ciencia y tecnología, una acorde a los tiempos y leyes del mercado, y otra a los tiempos de la diversidad ecológica y comunitaria. El primero argumenta que sólo poniendo precio a la Naturaleza es posible resguardarla y argumenta que proletarizando la sociedad es posible sacarlos de la pobreza "basta escuchar los preceptos del Banco Mundial y del Foro Económico Mundial de Davos, que pretenden, bajo el término desarrollo sostenible combatir aquella 
pobreza que el Fondo Monetario Internacional está causando a través de medidas de ajuste (Gabriel y López y Rivas 2005:20)”. Por otro lado, el discurso alternativo basado en la diversidad social y ecológica declara que se debe incluir la complejidad social y ambiental, en términos de la socialización de las alteridades sociedades con la naturaleza; sin olvidar, como señala Escobar- la deuda externa, la desigualdad, la protección del patrimonio natural y genético de la región (1999:79), ni las racionalidades culturales del complejo sistema de valores, ideologías, significados, prácticas productivas y estilos de vida (Leff et. al. 2005:9). Esta concepción busca alternativas creadas a través de redes de acción social multiculturales, multidisciplinarias y plurales que estén gobernadas por relaciones horizontales y nutridas y por consideraciones éticas como la reciprocidad, la confianza y la cooperación.

La sustentabilidad desde la alteridad está construyendo alternativas que tienen como puntos medulares cuatro dimensiones: ecológicas, sociales, económicas y políticas, la conjugación de ellas hablan de la complejidad social y ecológica que existe en el planeta. El desarrollo sustentable alternativo promueve que los individuos se hagan cargo de sí mismos edificando proyectos de vida familiares y comunales en sus lugares de origen, evitando con esto, la migración a los centros urbanos donde se forman cordones de miseria y de riesgo social.

Un ejemplo de este proceso de construcción de un discurso sustentable de respeto a la diversidad socioecológica se está llevando a cabo con (y no para) la comunidad de San Sebastián Villanueva, Acatzingo, Puebla, México donde se encuentra un grupo de campesinos llamado Sociedad productiva para el desarrollo de Villanueva (en adelante, soproDevi). Esta organización busca construir estrategias que mantengan su proyecto de vida ante la crisis económica que vive el país y el mundo. Esta experiencia muestra cómo con el establecimiento de redes interorganizacionales y académicas es posible construir proyectos de beneficio mutuo que modifican el aparente irremediable destino a la pobreza, la migración y el deterioro ambiental bajo el cual se encuentran en riesgo miles de comunidades en América Latina. Es importante entonces difundir de manera amplia estas experiencias, así como hallar coincidencias con otras que también constituyéndose bajo estos principios. También prueba que la relación conocimiento-producciónbienestar puede tener un nicho mucho más cercano, productivo y ecológicamente respetuoso, en contraposición a los programas de desarrollo sustentable que conciben a los seres humanos y a la Naturaleza que los circunscribe, como recursos explotables. Además, esta experiencia permite la reapropiación del entorno ético y político de las comunidades, dando lugar a que generen sus propias estrategias y recursos de subsistencia y reproducción social sin menoscabo de su integridad familiar, comunitaria e identidad. 


\section{Bibliografía}

Assies, Willem, Gemma van der Haar and Andre Hoekema (1999), The Challenge of Diversity, Indigenous Peoples and Reform of the State in Latin America. Amsterdam, Thela.

Barkin, David, Mario Fuente y Mara Rosas (2008), Strengthening Tradition, Innovating, Peasant contributions to technological innovation for sustainability. IV Globelics Conference at Mexico City, September 22-24 2008. Disponible en: http://globelics_conference2008.xoc.uam.mx/papers/ David_Barkin_Strengthening_Tradition.pdf. Consulta del 2 de enero de 2009.

Barkin, David and Carlos Paillés (2002), "NGO- collaboration for ecotourism: a strategy for sustainable regional development in Oaxaca”, Current issues in Tourism (5:3), 245-253.

Ídem (2000), "Water and forest as instruments for sustainable regional development”, in International Journal of Water 1, 1: 71-79.

Barkin, David. (1998). Riqueza, pobreza y desarrollo sustentable. México, Editorial Jus.

Ídem (1991), Un desarrollo distorsionado: la integración de México a la economía mundial, México, Siglo XXI/UAM-X.

Becerra, Andrea (2006), ILSA. Revista El Otro Derecho 34. Movimientos Sociales y Luchas por el Derecho Humano al Agua en América Latina. En Polis N ${ }^{\circ} 14$, Revista de la Universidad Bolivariana, Santiago. Disponible a texto completo en: http://www.revistapolis.cl/polis\%20final/14/bece.htm, visitado el 28 de febrero de 2009.

Beck, Ulrich (s/d), “La irresponsabilidad organizada”. Consultado en: perso.gratisweb.com/carlosmanzano/Beck01.htm, el 24 de noviembre de 2007.

BID. CAF. FONPLATA (2000), Plan de acción para la Integración de la Infraestructura Regional en América del Sur. Montevideo. BID/Corporación Andina de Fomento/Fondo Financiero para el Desarrollo de la Cuenca del Plata. Disponible en: http://www.iirsa.org/BancoConocimiento/O/ origenes/origenes.asp?CodIdioma=ESP\&CodSeccion=117 Consulta del 4 de mayo de 2009.

Blauert, Jutta y Simón Zadek (1999), .Mediación para la sustentabilidad. Construyendo políticas desde las bases. México, Plaza y Valdés. CIESAS. Carson, Rachel L. (2001 [1962]). Primavera Silenciosa. Barcelona, Crítica/Drakontos.

Crush, Jonathan (1998), The Power of Development. London, Routledge. 
Escobar, Arturo (1999), “El desarrollo sustentable: diálogo de discursos”, en Escobar, Arturo (comp.) El final del salvaje. Naturaleza, cultura y política en la antropología contemporánea. Santafé de Bogotá, CEREC. ICAN, pps: 75-97.

Ídem (1998), "Whose knowledge, whose nature? Biodiversity, conservation, and the Political Ecology of Social Movements”, en Journal of Political Ecology (5), 53-82.

Ídem (1997), Biodiversidad, Naturalezay cultura: localidad y globalidad en las estrategias de conservación. México, Centro de Investigaciones interdisciplinarias en Ciencias y Humanidades/Universidad Autónoma de México.

Ídem (1995), Encountering development: the making and unmaking of the third world. New Jersey, Princenton University Press.

Esteva, Gustavo (1999), “Development”, en Sachs, Wolfgang (editor) The development dictionary. A guide to knowledge as power, London, Zed Books.

Enkerlin, Hoeflich Ernesto (1997), Ciencia Ambiental y Desarrollo Sustentable. México, International Thomson Editores.

Foster, John Bellamy and Brett, Clarck (2008), “Rachel Carson’s Radical Ecological Critique”. Monthly Review. January 2008. Vol. 50, Issue 8. Disponible en: http://www.monthlyreview.org/080201foster-clark.php, Consulta del 7 de abril de 2008 .

Foucault, Michael (2005[1976]), Historia de la sexualidad. Vol. 1 La voluntad de saber. México, Siglo XXI.

Ídem (2002[1997]), Defender la sociedad. México, Fondo de Cultura Económica.

Flórez, Margarita (2006), “La IIRSA: ¿un lenguaje común?”, en Deslinde, $\mathrm{N}^{\circ} 40$ Septiembre-Noviembre de 2006. Disponible en: http:// www.deslinde.org.co/files/La \% 20 IIR S A \% $20 \%$ C $2 \%$ B F Un \%20lenguaje\%20com\%C3\%BAn.pdf. Consulta del 3 de mayo de 2009.

Funtowicz Silvio O. y Jerome R. Ravetz (2000), La ciencia posnormal. Ciencia con la gente. Barcelona, Icaria editorial.

Gabriel, Leo y Gilberto López y Rivas (2003), Autonomías Indígenas en América Latina. Nuevas formas de convivencia política. México, Plaza y Valdés/UAM.

Galeano, Eduardo. (2004[1971]), Las venas abiertas de América Latina. México, Siglo XXI. 
Ídem(1989), El libro de los abrazos. España, Siglo XXI Editores. También disponible en: http://www.librosgratisweb.com/pdf/galeano/el-libro-de-losabrazos.pdf

Georgescu-Roegen, Nicholas (1971), The Entropy Law and the Economic Process. Cambridge, Harvard University Press.

FOBOMADE e INCLUIR (2004), “IIRSA: un camino para vaciar América Latina”, en Biodiversidad Sustento y Culturas. Cuadernillo No. 19. Montevideo, GRAIN. Disponible en: http://www.grain.org/biodiversidad_files/ IIRSA-1.pdf. Consulta del 2 de mayo de 2009.

IUCN, PNUMA, WWF (1980), Primera estrategia mundial de la conservación. Gland, Suiza. IUCN, PNUMA, WWF. Disponible en: http:// www.otrodesarrollo.com/biblioteca/BibliotecaDesarrolloSustentable.htm Consulta del 13 de noviembre de 2008.

Korten, David (1999), The Post Corporate World: Life After Capitalism, Barret Koehler Publishers, Inc. Kumarian Press, Inc.

Leff, Enrique, Arturo Argueta, Eckart Boege, y Carlos Walter Porto Gonçalves (2005), “Más allá del desarrollo sustentable. La construcción de una racionalidad ambiental para la sustentabilidad: una visión desde América Latina”. Futuros. Revista Trimestral latinoamericana y caribeña de desarrollo sustentable, núm 9, año 2005, Vol 3. Disponible en: http:// www.revistafuturos.info/futuros_9/ds_al_1.htm. Consulta del 29 de marzo de 2008.

Ídem (1998), Saber ambiental, sustentabilidad, racionalidad, complejidad, poder. México, Siglo XXI.

Meadows, Dennis et. al. (1972), Los límites del crecimiento. México, FCE.

Manifiesto por la vida (2004), “Una ética para la sustentabilidad”, en Riechmann, Jorge, (coord.) Ética Ecológica. Propuestas para una reorientación. Uruguay, Nordan Comunidad, pps. 15-28

ONU (1972), Declaración de Estocolmo. Conferencia de las Naciones Unidas sobre el Medio Ambiente Humano. Estocolmo, ONU. Disponible en: http://www.prodiversitas.bioetica.org/doc89.htm. Consulta del 2 de marzo de 2008.

Public Papers of the Presidents of the United States (1949). Harry S. Truman (1945-1953), Jan 1 to Dec 31 1949. Washington. D.C, PPPUS, pps 114115.

Rifkin, Jeremy (1996), El fin del trabajo, nuevas tecnologías contra puestos de trabajo: el nacimiento de una nueva era. México, Paidós. 
Rifkin, Jeremy y Ted Howard (1990), Entropía. Hacia el mundo invernadero. Barcelona, Urano.

Rist, Gilbert (2003), The History of Development: From Western Origins to Global Faith, Expanded Edition, London, Zed Books.

Roitman Rosenmann, Marcos (2009), La digna rabia y la otra política. Disponible en: http://www.jornada.unam.mx/2009/01/04/index.php? section=opinion \&article=015a1pol. Consulta del 4 de enero de 2009 .

Rosas, Mara (2009), Actividades no-proletarias generadoras de excedentes: una contribución a la economía ecológica. Tesis doctoral. México, UAM.

Sachs, Ignacy (1982), Ecodesarrollo: desarrollo sin destrucción. México, Colmex.

Sachs, Wolfgang (1999), The development dictionary. A guide to knowledge as power. London, Zed Books.

Santiago, Evelinda y David Barkin (2006), “Local Participation and Sustainability: Lessons from three communities in Oaxaca, in: Reclaiming Sustainability: Space, Power and the Commons, Johnston, José, Mike Gismondi and James Goodman (eds.), Broadview Press, pps. 183-201.

Santiago, Evelinda (2009), “Tecnología alternativa, administración integral de los recursos naturales y la participación local de dos comunidades oaxaqueñas”, en: Colección AMER Oaxaca 2005. Tomo IV: Caminos por andar en la gestión sustentable de los recursos naturales, Asociación Mexicana de Estudios Rurales (AMER). H. Consejo Editorial de la Cámara de Diputados. En prensa.

Ídem (2007), “Biodiversidad, cultura y territorio”. Territorios. Revista de Estudios Regionales y Urbanos. Núm. 16 y 17. Internacionalista Universidad del Rosario, Colombia, pps. 127-148.

Ídem (2004), “La participación local en procesos productivos sustentables: estudio de caso en tres comunidades oaxaqueñas”. Tesis Doctoral. ITO. También disponible en: http://www.eumed.net/tesis/esj/index.htm

Shiva, Vandana (2003), Las guerras del agua. Privatización, contaminación y lucro. México, Siglo XXI.

Ídem (1997), Biopiracy. The plunder of nature and knowledge. Boston, South End Press Collective.

Toledo, Víctor Manuel (2000), La paz en Chiapas: ecología, luchas indígenas y modernidad alternativa. México, Quinto Sol. 
Polis, Revista de la Universidad Bolivariana, Volumen 8, $N^{\circ}$ 24, 2009

Ídem (1999), El otro zapatismo: luchas indígenas de inspiración ecológica en México. México, UNAM/Quinto Sol.

Ídem (1997), Amenazas globales, resistencias locales: la alianza de las comunidades indígenas con su biodiversidad en México. Informe preparado para el IV Foro del Ajusco, PNUMA y Colmex.

Wackernagel, Mathis y Rees, William (1995), Our ecological footprint: reducing human impact on the Earth, New Society Publishers. 